\title{
Greywater Treatment of Emerging Pollutant Linear Alkylbenzene Sulfonate By Adsorption With Leather Shave Waste Activated Carbon
}

\section{Henrique Baldi Faccenda}

University of Passo Fundo: Universidade de Passo Fundo

Flávia Melara

University of Passo Fundo: Universidade de Passo Fundo

Gabriel Damini

University of Passo Fundo: Universidade de Passo Fundo

Marcelo Godinho

University of Caxias do Sul: Universidade de Caxias do Sul

\section{Christian Manera}

University of Caxias do Sul: Universidade de Caxias do Sul

Jeferson Steffanello Piccin ( $\nabla$ jefersonpiccin@upf.br)

University of Passo Fundo https://orcid.org/0000-0002-7901-8101

\section{Research Article}

Keywords: Cleaning products, Domestic waste, Emerging contaminant, Micelle, Surfactant adsorption, Wastewater treatment

Posted Date: September 3rd, 2021

DOl: https://doi.org/10.21203/rs.3.rs-813084/v1

License: (c) (1) This work is licensed under a Creative Commons Attribution 4.0 International License.

Read Full License 


\section{Greywater treatment of emerging pollutant linear alkylbenzene sulfonate by adsorption with leather shave waste activated carbon}

Henrique Baldi Faccenda ${ }^{1}$, Flávia Melara ${ }^{1}$ Gabriel Damini ${ }^{2}$, Marcelo Godinho ${ }^{3}$, Christian Manera ${ }^{3}$, Jeferson Steffanello Piccin ${ }^{1 *}$

1 University of Passo Fundo (UPF), Faculty of Engineering and Architecture (FEAR), Postgraduate Program in Civil and Environmental Engineering (PPGEng), Passo Fundo-RS, Brazil

2 University of Passo Fundo (UPF), Faculty of Engineering and Architecture (FEAR), Chemical Engineering Course, Passo Fundo-RS, Brazil

${ }^{3}$ University of Caxias do Sul (UCS), Postgraduate Program in Process Engineering and Technologies, Caxias do Sul, Rio Grande do Sul, Brazil.

* Corresponding author e-mail: jefersonpiccin@upf.br

Phone number: +5554999100530

\section{Abstract}

This study aims to evaluate the use of leather shave waste activated carbon (ACLW) as an alternative for the treatment of wastewaters containing Linear Alkylbenzene Sulphonate (LAS). Batch adsorption tests were carried out ( $\mathrm{pH}$ effect, isotherms, kinetics). The activated carbon was tested for its life cycle by desorption with solvents and it was also evaluated as a real wastewater treatment for bath greywater. Under the optimum $\mathrm{pH}$ of 2.5 , the equilibrium isotherms correlated better with the Freundlich and RedlichPeterson models, indicating a possible multilayer formation, and classifying the isotherm as having a high affinity. Adsorption was shown to be endothermic $\left(\Delta \mathrm{H}^{0}=+73.89 \mathrm{~kJ} \mathrm{~mol}^{-1}\right)$, entropy driven $\left(\Delta \mathrm{S}^{0}=+0.46\right.$ $\mathrm{kJ} \mathrm{mol}^{-1} \mathrm{~K}^{-1}$ ) and occurs spontaneously. The kinetic studies showed a best correlation with the pseudosecond order model, with activation energy of $27.5 \mathrm{~kJ} \mathrm{~mol}^{-1}$. The use of ethanol solution was effective for the regeneration of the adsorbent. The adsorption was applied in real wastewater, removing contaminants from bath greywater, especially anionic surfactants with up to $95 \%$ removal efficiency.

Keywords: Cleaning products. Domestic waste. Emerging contaminant. Micelle. Surfactant adsorption. Wastewater treatment.

\section{INTRODUCTION}

The main components of cleaning and personal care products are surfactants. These substances promote the removal of oil and grease molecules, facilitating the cleaning of the environment (Knepper and Berna 2003). Present even in the industrial sector, they are common in fabric, paint, polymer, pesticide, pharmaceutical, mining, oil and cellulose factories (Ying 2006). The surfactant structure is composed of the polar head hydrophilic, and the apolar tail hydrophobic (Ying 2006), and are considered emerging contaminant by Unesco (2015). Therefore, it is essential to track the impacts that wastewater of these pollutants on the environment.

In residential environments, surfactants are the main contaminants of greywater, that is, water from bathing and washing and cleaning activities. In Brazil, for example, about $44 \%$ of the population does not have adequate sanitary conditions (SNIS 2018), which means that a large part of the wastewater containing surfactants ends up reaching water resources and the soil in an uncontrolled manner.

Alkylbenzene Sulfonate Linear (LAS) is the market leader for anionic surfactants in Brazil, with $84 \%$ of 
consumption, followed by your homologue Sodium Dodecyl Benzene Sulfonate (SDBS), responsible for 9\% of the shares (BNDES 2014). The LAS molecule has a sulfonated aromatic ring in the para position, attached to a linear alkyl chain except for the terminal carbons. LAS has various homologues, which vary as a function of different alkyl chain lengths and aromatic ring positions along the linear alkyl chain (OECD 2005).

The potential toxicity of surfactants has been the subject of regulatory restrictions on their use and disposal in several countries (Rebello et al. 2013). In humans, they are mainly responsible for disturbing endocrine systems (Bonilla-Petriciolet et al. 2017). In addition, they can be fatal if consumed in amounts greater than 150 grams and contact in solutions greater than $20 \%$ cause irritation to the epidermis. Repetitive exposure can cause dermatitis and severe respiratory problems (Kumar et al. 2014). Its toxicological effects on the environment are proportional to the exposure time and the concentration in liquid medium. Exposures of up to $15 \mathrm{mg} \mathrm{L}^{-1}$ of SDBS experimentally induced in fish of the species Sparus aurata L. resulted in significant inhibition of their fertility, in addition to morphological changes in their kidneys and spleen (Kumar et al. 2014). Another experiment with fish from the Scophthalmus maximus L. family resulted in the mortality of $50 \%$ of the population within four hours of exposure to $10 \mathrm{mg} \mathrm{L}^{-1}$ of SDBS (Kumar et al. 2014).

Some surfactants can present bactericidal properties (Rebello et al. 2013). The LAS showed a strong inhibition of the activity of nitrifying bacteria, which compromises ammonia mineralization processes and the nitrogen cycle (Brandt et al. 2001). Still, Jurado et al. (2011) affirm that surfactants are bioaccumulative in some organisms, as found for some crustaceans and fish. Conventional water and sewage treatment processes are not satisfactory effective in removing some micropollutants, such as surfactants (Petrovic et al. 2003). The SDBS showed toxic effects on gram-negative bacteria, altering the functioning of the cytoplasm and organelles such as mitochondria, peroxisomes, nucleus and plasma membrane (Kumar et al. 2014).

Complementary wastewater treatment methods have been investigated for surfactant removal, such as membrane separation processes, electro-fenton and bioremediation (Palmer and Hatley 2018), and adsorption techniques (Schouten et al. 2007; Wu and Pendleton 2001). Adsorption has been studied as a method of removing surfactants present in water, as it is capable of retaining organic pollutants even at low concentrations (Rampelotto 2014; Patil and Munavalli 2016). In this operation, the use of activated carbon as an adsorbent stands out, as it has high porosity and surface area, it can originate from low-cost waste and has a strong interaction with the hydrophobic portion of the surfactants, thus promoting the adsorption of the solubilized material on its surface. (Wu and Pendleton 2001).

Schouten et al. (2007) emphasize that adsorption is a compact and inexpensive method, which can be installed in small laundries. Siyal et al. (2020) attests that the best option for adsorption of anionic surfactants such as LAS is activated carbon when the adsorption capacity and cost benefit are evaluated. However, there are few scientific articles that review the theme of surfactants treatment by adsorption on activated carbon (Siyal et al. 2020).

The mechanisms of adsorption are related to electrostatic forces, hydrogen bonds, van der Waals forces and dipole-dipole (Piccin et al. 2017). Factors that affect adsorption are $\mathrm{pH}$ of solution, temperature, type of solvent, nature of solute, surface area of adsorbent and the structure of its pores (Cooney 1998). Chang et 
al. (2018) states that chemical adsorption of surfactants occurs only when the solid adsorbent has hydrophilic properties and interacts with polar functional groups of the head of surfactants, characterized by slow and monolayer adsorption. Leather shave waste is a waste that has great potential when transformed into activated carbon, with satisfactory results in the removal of dyes and surfactants (Mi-Na et al. 2006; Piccin et al. 2013; Manera et al. 2018). Its use as activated carbon would be a solution to add value to waste, increasing its life cycle before final disposal.

In this context, this research aims to evaluate whether the adsorption by activated carbon of leather shave waste is capable of removing anionic surfactants in aqueous solution, establishing the adsorption mechanisms and applying to real greywater wastewater.

\section{MATERIAL AND METHODS}

\subsection{Materials}

The activated carbon from leather shave waste (ACLW) was kindly provided by the Energy and Bioprocess Laboratory (LEBIO) of the Graduate Program in Process and Technology Engineering (PGEPROTEC) at the University of Caxias do Sul (UCS). The leather chips underwent a pyrolysis process in a semicontinuous pilot screw reactor at $450^{\circ} \mathrm{C}$. Afterwards, it was demineralized with $\mathrm{HCl}\left(3 \mathrm{~mol} \mathrm{~L}^{-1}\right)$, washed and dried. Activation took place with $\mathrm{CO}_{2}$ in a fixed bed tubular reactor at $900^{\circ} \mathrm{C}$ for $6 \mathrm{~h}$. More information about ACLW production operating conditions is available at Manera et al. (2016). LAS was purchased at the Sigma Aldrich, with $80 \%$ purity.

\subsection{Adsorption assays}

The adsorption tests were performed with aqueous solutions of Alkylbenzene Sulfonate Linear (LAS, Sigma Aldrich, 80\%). The concentrations of LAS in aqueous solution were determined by UV-Vis spectrophotometry at a wavelength of $223 \mathrm{~nm}$ (Tecnal Spec/UV-5100) (Schouten et al. 2009). Adsoprtion experiments were carried out following the methodology of Piccin et al. (2017).

\section{The effect of $\mathrm{pH}$ in the adsorption was evaluated in the range of 2.5 to 8.5 . The $\mathrm{pH}$ was adjusted with $\mathrm{NaOH}$} or $\mathrm{HCl} 0.1 \mathrm{~mol} \mathrm{~L}{ }^{-1}$ solutions. For this proposed $50 \mathrm{~mL}$ LAS aqueous solution containing $100 \mathrm{mg} \mathrm{L}^{-1}$ was put in contact with $0,05 \mathrm{~g}$ of ACLW at $100 \mathrm{rpm}, 25^{\circ} \mathrm{C}$ and 120 minutes run (Tecnal/TE021). After that, the concentration of LAS in the supernatant was determined and the adsorption capacity calculated according to equation 1 :

$$
q=\frac{V}{m}\left(C_{0}-C\right)
$$

were $\mathrm{V}$ is the volume $(\mathrm{L}), \mathrm{m}$ is the adsorbent mass $(\mathrm{g})$ and $\mathrm{C}_{0}$ and $\mathrm{C}$ are the initial and final LAS concentration $\left(\mathrm{mg} \mathrm{L}^{-1}\right)$. All adsorption experiments were carried out in duplicate and experimental value was presented by mean \pm standard deviation.

Equilibrium isotherms were carried out using $50 \mathrm{~mL}$ of aqueous solution of LAS at initial concentration $\left(\mathrm{C}_{0}\right)$ varying between 50 to $400 \mathrm{mg} \mathrm{L}^{-1}$. The solutions were placed in contact with $0.02 \mathrm{~g}$ of ACLW at constant temperature $\left(15^{\circ} \mathrm{C}, 25^{\circ} \mathrm{C}, 35^{\circ} \mathrm{C}\right.$ and $\left.45^{\circ} \mathrm{C}\right)$ under $100 \mathrm{rpm}$ agitation (Tecnal/TE021). Equilibrium 
was defined when the concentration of LAS in the supernatant did not change (approximately $8 \mathrm{~h}$ ) In the kinetics experiments, $250 \mathrm{~mL}$ of $100 \mathrm{mg} \mathrm{L}^{-1}$ of LAS and $0.05 \mathrm{~g}$ of ACLW were mixed at $100 \mathrm{rpm}$ for $180 \mathrm{~min}$ (Tecnal/TE021). Aliquots were collected and LAS concentration determined in predefined time intervals.

Data analysis of adsorption isotherms and kinetics were carried out by models following Table 1 using Matlab software (Mathworks, online version). Computer routines are available at < https://www.dropbox.com/sh/elq2br3319ccbds/AAB2CTE2Hgb8bG_0Ue48tfLfa?dl=0 >.

Table 1: Adsorption isotherms and kinetics models used in adsorption data analysis

\begin{tabular}{|c|c|c|c|}
\hline Model & Parameters & Equation & \\
\hline \multicolumn{4}{|c|}{ Adsorption isotherms models } \\
\hline $\begin{array}{l}\text { Langmuir } \\
(1918)\end{array}$ & $\begin{array}{l}\mathrm{C}_{\mathrm{e}} \text { is the equilibrium concentration }\left(\mathrm{mg} \mathrm{L}^{-1}\right) \text {, } \\
\mathrm{q}_{\mathrm{m}} \text { is the maximum adsorption capacity }\left(\mathrm{mg} \mathrm{g}^{-}\right. \\
\left.{ }^{1}\right) \text { and } \mathrm{K}_{\mathrm{L}} \text { is the Langmuir constant }\left(\mathrm{L} \mathrm{mg}^{-1}\right)\end{array}$ & $\mathrm{q}_{\mathrm{e}}=\frac{\mathrm{K}_{\mathrm{L}} \mathrm{q}_{\mathrm{m}} \mathrm{C}_{\mathrm{e}}}{1+\mathrm{K}_{\mathrm{L}} \mathrm{C}_{\mathrm{e}}}$ & (2) \\
\hline $\begin{array}{l}\text { Freundlich } \\
(1906)\end{array}$ & $\begin{array}{l}\mathrm{K}_{\mathrm{F}} \text { is the Freundlich constant }\left(\mathrm{mg} \mathrm{g}^{-1} \text { or } \mathrm{mg} \mathrm{L}^{-}\right. \\
\left.{ }^{1}\right) \text { and } \mathrm{n}_{\mathrm{F}} \text { is the heterogeneity factor }\end{array}$ & $\mathrm{q}_{\mathrm{e}}=\mathrm{K}_{\mathrm{F}} \mathrm{C}_{\mathrm{e}}^{1 / \mathrm{n}_{\mathrm{F}}}$ & (3) \\
\hline $\begin{array}{l}\text { Redlich and } \\
\text { Peterson } \\
\text { (1959) }\end{array}$ & $\begin{array}{l}K_{R P} \text { and } a_{R P} \text { are the Redlich-Peterson } \\
\text { constants }\left(\mathrm{L} \mathrm{g} \mathrm{g}^{-1} \text { and } \mathrm{L}^{\mathrm{B}} \mathrm{g}^{-\mathrm{B}} \text {, respectively), }\right. \\
\text { where } \beta \text { is an exponent that ranges from } 0 \text { to } 1\end{array}$ & $\mathrm{q}_{\mathrm{e}}=\frac{\mathrm{K}_{\mathrm{RP}} \mathrm{C}_{\mathrm{e}}}{1+\mathrm{a}_{\mathrm{RP}} \mathrm{C}_{\mathrm{e}}^{\beta}}$ & (4) \\
\hline
\end{tabular}

\section{Adsorption kinetics models}

$\mathrm{q}_{\mathrm{t}}\left(\mathrm{mg} \mathrm{g}^{-1}\right)$ is considered the adsorption

Pseudo first- capacity at time $\mathrm{t}(\mathrm{min}), \mathrm{q}_{\mathrm{e}, 1}\left(\mathrm{mg} \mathrm{g}^{-1}\right)$ the

order Lagergren adsorption capacity at equilibrium and $\mathrm{K}_{1}$

$$
q_{t}=q_{e, 1}\left(1-\exp \left(-K_{1} t\right)\right)
$$

$\left(\mathrm{min}^{-1}\right)$ is the pseudo first-order kinetic

constant

Pseudo second- $\quad \mathrm{K}_{2}\left(\mathrm{~g} \mathrm{mg}^{-1} \mathrm{~min}^{-1}\right)$ is the pseudo second-order

order kinetic constant and $\mathrm{q}_{\mathrm{e}, \mathrm{s}}\left(\mathrm{mg} \mathrm{g}^{-1}\right)$ the

Ho and Mckay adsorption capacity at equilibrium

$$
q_{t}=\frac{K_{2} q_{e, 2}^{2} t}{1+K_{2} q_{e, 2} t}
$$

(2000)

Adapted from Bonilla-Petriciolet et al. (2019).

\subsubsection{Regeneration by desorption cycles}

To regenerate assays, $50 \mathrm{~mL}$ of LAS solution with a concentration of $100 \mathrm{mg} \mathrm{L}^{-1}$ at the ideal $\mathrm{pH}$ and 0,05 $\mathrm{g}$ of ACLW were added in Falcon $\mathbb{R}$ tubes, which remained in contact for 30 minutes at $25^{\circ} \mathrm{C}$ and $100 \mathrm{rpm}$. After the adsorption step, the material was centrifuged for five minutes at $3000 \mathrm{rpm}$ (Parsec/CT0603) to remove the solution, performing the concentration measurement by spectrophotometry.

For desorption, $20 \mathrm{~mL}$ of the solvent Ethanol $80 \%$ was added in the tube with de adsorbent used in the adsorption step, maintaining it for 30 minutes at $25{ }^{\circ} \mathrm{C}$ and $100 \mathrm{rpm}$. The eluent was removed by centrifugation and the concentration was determined by spectrophotometry. The adsorbent was washed with $10 \mathrm{~mL}$ distilled water and centrifuged again. The wash step is important to equilibrate the $\mathrm{pH}$ and to 
remove the eluent residues.

The tests were carried out in duplicate, and the results were analysed in terms of removal per cycle calculated according to equations 7 .

$$
\operatorname{Removal}(\%)=\frac{\mathrm{C}_{0}-\mathrm{C}}{\mathrm{C}_{0}} \cdot 100
$$

\subsubsection{Greywater treatment}

In order to evaluate the treatment of real wastewater, the adsorption with ACLW was applied to greywater from a domestic bath. The greywater collection was performed during a regular bath of a person, by pumping the wastewater present in the bathroom drain.

To determine the ideal adsorbent dosages, five different mass of ACLW varying between 0.2 and $3.0 \mathrm{~g} \mathrm{~L}^{-1}$ were added to $50 \mathrm{~mL}$ aliquots of raw wastewater in falcon tubes. The tubes were shaken at $100 \mathrm{rpm}$ and 25 ${ }^{\circ} \mathrm{C}$ for $1 \mathrm{~h}$. Afterwards, the samples were centrifuged at $3000 \mathrm{rpm}$ for 5 minutes, for separation and analysis of residual surfactant. In addition, aliquots of the raw wastewater and treatments were monitored by spectrophotometric scanning in the region between 200 to $800 \mathrm{~nm}$ (Eppendorf/BioSpectrometer Kinetic) (Santos et al. 2015). According to this methodology, the treatment efficiency can be described as a function of the area under the absorption band from 300 to $800 \mathrm{~nm}$.

The greywater was characterized according to $\mathrm{pH}$ (Method 4500), colour (Method 2120) and turbidity (Method 2130) using the methodology of American Public Health Association (2017). The concentration of surfactants in the actual raw and treated wastewater was carried out using the methylene blue active substances method (MBAS, Method 5540), to avoid interference from other materials.

\section{RESULTS AND DISCUSSIONS}

\subsection{Adsorption experiments}

The Fig. 1 shows the summarized results of LAS adsorption in aqueous solution by ACLW. The pH is one the most important parameters in the adsorption, due to nature of superficial charges of adsorbent. In this case, LAS adsorption is increased in acid conditions and $\mathrm{pH} 2.5$ is used to other experiments. Adsorption equilibrium curves are shown in Fig. 1b. Fig. 1c shows the adsorption kinetics, to evaluate the LAS adsorption rate by ACLW. Finally, Fig. 1d shows the life cycle experiments of the adsorbent material, carried out through successive adsorption and desorption tests.

\subsubsection{The effect of $\mathrm{pH}$}

In the Fig. 1a is possible to observe the increase of adsorption capacity with the adsorbate in acidic conditions, with a $\mathrm{pH}$ of 2.5, showing an adsorption capacity of $94.78 \mathrm{mg} \mathrm{g}^{-1}$. According to Manera et al. (2018), the point of zero charge ( $\mathrm{pH}_{\mathrm{PZC}}$ ) of ACTW is around $\mathrm{pH}$ 7.7. Then, in acidic conditions, the leather residue activated carbon has a protonated surface by its carboxyl and hydroxyl groups $\left(\mathrm{COOH}_{2}^{+}\right.$and $\left.\mathrm{OH}_{2}^{+}\right)$. This positive charge is responsible for attracting anions, which enables the affinity with the anionic 
surfactant LAS. Still, in an acidic environment, there is an increase in the electrostatic interaction of the coal surface with the LAS sulfonate group $\left(\mathrm{SO}_{3}{ }^{-}\right)$. In addition, at basic $\mathrm{pH}$, the $\mathrm{OH}$ - ion can compete with the active sites with the hydrophilic group of the LAS.

Fig. 1: LAS adsorption by ACLW in aqueous solution: a) Effect of $\mathrm{pH}\left(\mathrm{C}_{0}=100 \mathrm{mg} \mathrm{L}-1, \mathrm{~m} / \mathrm{V}=1.0 \mathrm{~g} \mathrm{~L}^{-1}\right.$; $\left.\left.25^{\circ} \mathrm{C} ; 2 \mathrm{~h} ; 100 \mathrm{rpm}\right) ; \mathrm{b}\right)$ adsorption isotherms $\left(\mathrm{m} / \mathrm{V}=0.4 \mathrm{~g} \mathrm{~L}^{-1} ; \mathrm{pH} 2.5 ; 100 \mathrm{rpm}\right.$. Solid lines represents the Freundlich model fitting); c) Adsorption kinetics $\left(\mathrm{C}_{0}=100 \mathrm{mg} \mathrm{L}^{-1} ; \mathrm{m} / \mathrm{V}=0.2 \mathrm{~g} \mathrm{~L}^{-1} ; \mathrm{pH} 2.5 ; 100 \mathrm{rpm}\right)$. Solid lines represents the pseudo-second order model fitting); and d) recycle and reuse experiment $\left(\mathrm{C}_{0}=\right.$ $100 \mathrm{mgL}^{-1} ; \mathrm{pH} 2.5 ; 100 \mathrm{rpm} ; 30 \mathrm{~min} ; 25^{\circ} \mathrm{C} ; \mathrm{m} / \mathrm{V}=1.0 \mathrm{~g} \mathrm{~L}^{-1}$, using $80 \%$ ethanol as eluent)

a)

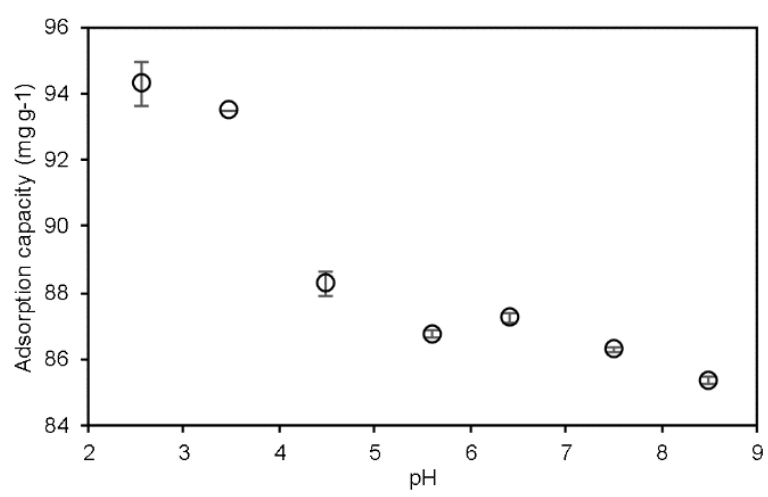

c)

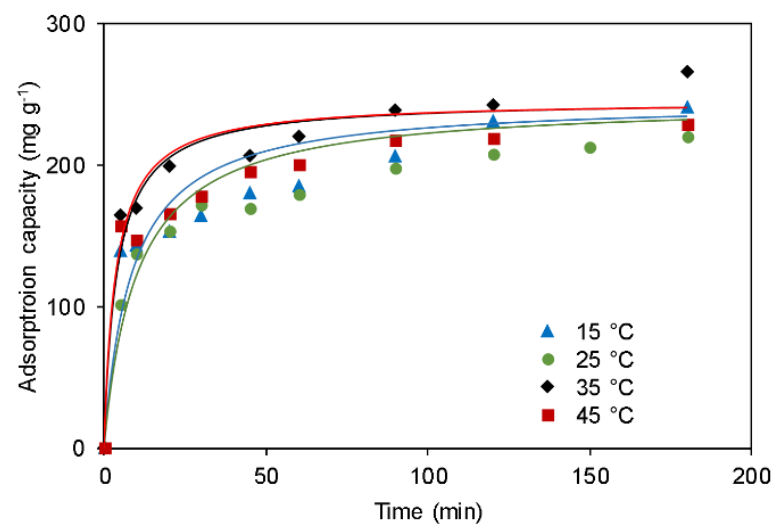

b)

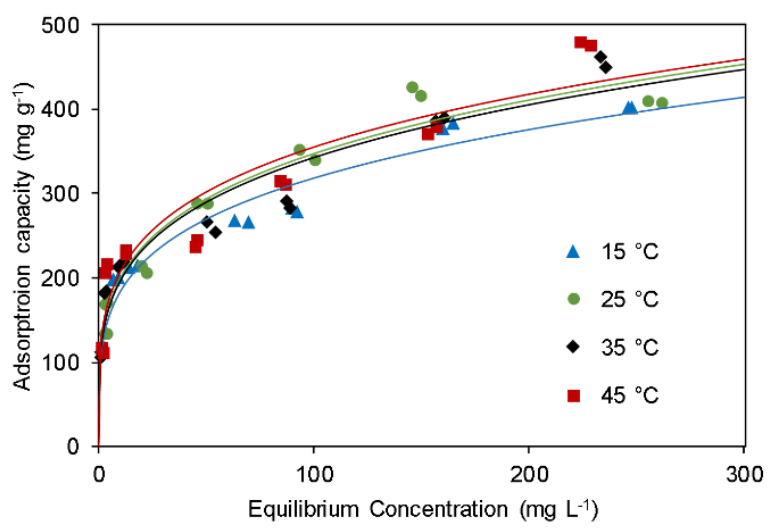

d)

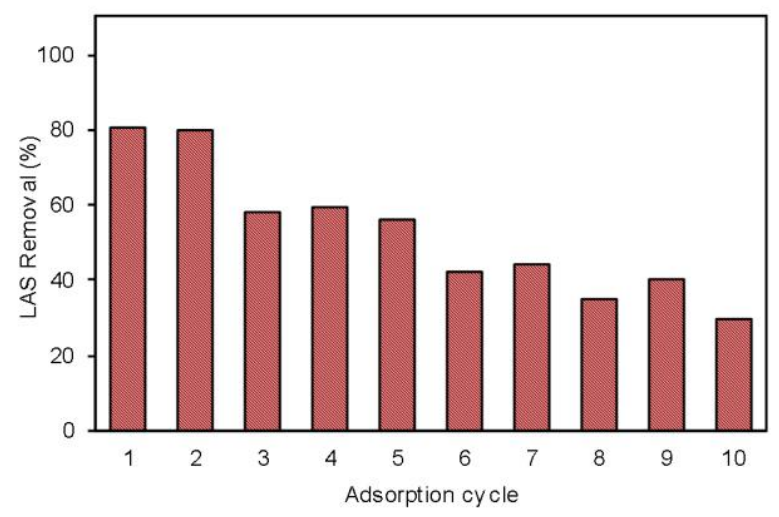

\subsubsection{Adsorption Equilibrium}

Fig. 1b shows the LAS adsorption isotherms by ACLW, showing the values of adsorption capacity in relation to the equilibrium concentration. At lower equilibrium concentrations there is a tendency for higher temperatures to result in greater adsorption capacities. However, with the increasing in equilibrium concentrations, although all experiments follow the direct correlation with the adsorption capacity, there is a slight oscillation between the temperatures that best correspond to the experiments. And for the highest equilibrium concentrations, the same initial pattern is observed again, conditioning the highest test temperatures to the highest adsorption capacities. At equilibrium concentrations close to zero the adsorption capacity is high, above $100 \mathrm{mg} \mathrm{L}^{-1}$. This is characteristic of $\mathrm{H}$ class isotherms according Giles et al. (1961) classification, that is, of high affinity that characterizes chemical adsorption or by electrostatic forces 
(Piccin et al. 2017).

204 The slope of the trend line shows slight verticalization with the increase in the equilibrium concentration.

205 This is a characteristic of subgroup 3 isotherms (Giles et al. 1961; Bonilla-Petriciolet et al. 2017). It means

206 a saturation of the monolayer in low concentrations and an increase in the intermolecular affinity of the

207 solute with the increase in concentration, giving evidence of multilayer formation.

208 The models applied to estimate the adsorption parameters are shown in Table 2. Both the Redlich-Peterson 209 and the Freundlich models presented estimated values with the best fit with the observed data. The solid

Table 2: Isotherm model parameters adjusted to the LAS adsorption equilibrium curves by ACLW

\begin{tabular}{|c|c|c|c|c|c|c|}
\hline \multicolumn{7}{|c|}{ Langmuir } \\
\hline $\begin{array}{c}\mathbf{T} \\
\left({ }^{\circ} \mathbf{C}\right)\end{array}$ & $\begin{array}{c}\mathrm{K}_{\mathrm{L}} \\
\left(\mathrm{L} \mathrm{mg}^{-\mathbf{1}}\right)\end{array}$ & $\begin{array}{c}\mathbf{q m} \\
\left(\mathrm{mg} \mathrm{g}^{-1}\right)\end{array}$ & & $\mathbf{R}^{2}$ & $\mathbf{R}^{2}$ adj & SSE \\
\hline 15 & 0.1315 & 357.1 & & 0.7940 & 0.7768 & 42.48613 \\
\hline 25 & 0.1293 & 389.8 & & 0.7960 & 0.7789 & 48.24565 \\
\hline 35 & 0.2081 & 365.8 & & 0.7190 & 0.6956 & 58.56132 \\
\hline 45 & 0.2533 & 367.3 & & 0.6476 & 0.6182 & 65.70714 \\
\hline \multicolumn{7}{|c|}{ Freundlich } \\
\hline $\mathbf{T}$ & $\mathbf{K}_{\mathbf{F}}$ & $n_{F}$ & & $\mathbf{R}^{2}$ & $\mathbf{R}^{\mathbf{2}}{ }_{\text {adj }}$ & SSE \\
\hline$\left({ }^{\circ} \mathbf{C}\right)$ & $\left(\mathrm{mg} \mathrm{L}^{-1}\right)$ & & & & & \\
\hline 15 & 105.7 & 4.170 & & 0.9526 & 0.9486 & 20.37856 \\
\hline 25 & 113.6 & 4.122 & & 0.9526 & 0.9486 & 24.10246 \\
\hline 35 & 112.3 & 4.127 & & 0.9289 & 0.9230 & 29.45335 \\
\hline 45 & 120.3 & 4.261 & & 0.8891 & 0.8798 & 36.86268 \\
\hline \multicolumn{7}{|c|}{ Redlich-Peterson } \\
\hline $\begin{array}{c}\mathbf{T} \\
\left({ }^{\circ} \mathbf{C}\right)\end{array}$ & $\begin{array}{r}K_{R P} \cdot 10^{-7} \\
\left(L g^{-1}\right)\end{array}$ & $\mathrm{aRP} \cdot 10^{-5}$ & $\boldsymbol{\beta}$ & $\mathbf{R}^{2}$ & $\mathbf{R}_{\text {adj }}^{2}$ & SSE \\
\hline 15 & 5.604 & 5.299 & 0.760 & 0.9526 & 0.9486 & 20.37866 \\
\hline 25 & 11.130 & 9.794 & 0.757 & 0.9491 & 0.9448 & 24.10246 \\
\hline 35 & 40.697 & 36.252 & 0.760 & 0.9289 & 0.9230 & 29.45335 \\
\hline 45 & 92.922 & 77.216 & 0.770 & 0.8891 & 0.8798 & 36.86268 \\
\hline
\end{tabular}

216 thermodynamics. The parameters of Gibb's free energy theory $\left(\Delta \mathrm{G}^{0}\right)$, summarized by equation 9.

217 According to it, $\Delta \mathrm{G} 0$ is correlated to the enthalpy adsorption $\left(\Delta \mathrm{H}^{0}\right)$ and entropy $\left(\Delta \mathrm{S}^{0}\right)$. Moreover, $\Delta \mathrm{G}^{0}$ is

218 calculated through the equilibrium constant $\left(\mathrm{K}_{\mathrm{e}}\right)$, according to equation 9. Thus, the Van't Hoff plot is

219 obtained, according to equation 10 (Bonilla-Petriciolet et al. 2017). 


$$
\Delta \mathrm{G}^{0}=-\mathrm{RT} \ln \left(\mathrm{K}_{\mathrm{e}}\right)
$$

$$
\ln \left(K_{e}\right)=-\frac{\Delta H^{0}}{R T}+\frac{\Delta S^{0}}{R}
$$

223

where, $\mathrm{R}$ is the universal gas constant $\left(8.314 \mathrm{~J} \mathrm{~mol} \mathrm{~K}^{-1}\right)$ and $\mathrm{K}_{\mathrm{e}}$ is the thermodynamic equilibrium constant. Fig. 2 shows the Van't Hoff graph, which correlates the equilibrium constant $\left(\mathrm{K}_{\mathrm{e}}\right.$, obtained by the RedlichPeterson model) with temperature. Table 3 summarizes the estimated values of thermodynamic parameters.

Fig. 2: Van't Hoff plot of LAS adsorption by ACLW (m/V=0.4gL-1; $\mathrm{pH} 2.5 ; 100 \mathrm{rpm})$

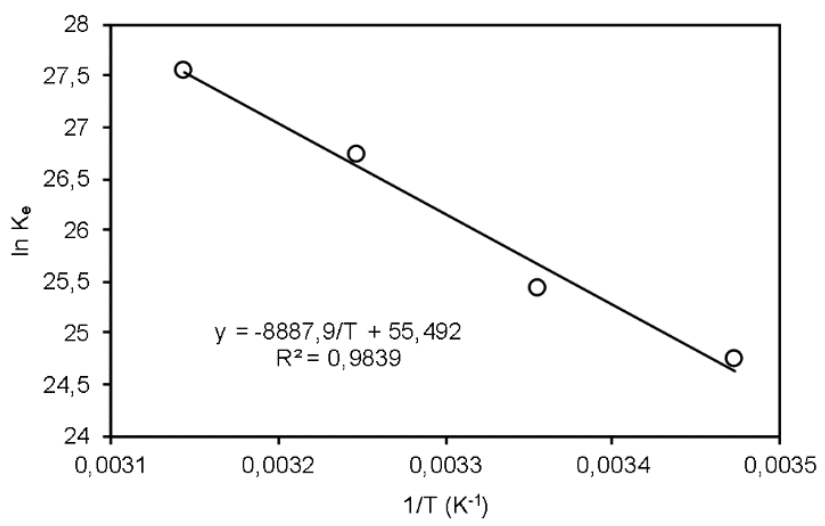

\begin{tabular}{|c|c|c|c|c|}
\hline \multicolumn{2}{|c|}{ Temperature } & \multirow{2}{*}{$\begin{array}{c}\Delta \mathrm{S}^{\circ} \\
\left(\mathrm{kJ} \mathrm{mol}{ }^{-1} \mathrm{~K}^{-1}\right)\end{array}$} & \multirow{2}{*}{$\begin{array}{c}\Delta \mathrm{H}^{\circ} \\
\left(\mathrm{kJ} \mathrm{mol}{ }^{-1}\right)\end{array}$} & \multirow{2}{*}{$\begin{array}{c}\Delta \mathrm{G}^{\circ} \\
\left(\mathrm{kJ} \mathrm{mol}^{-1}\right)\end{array}$} \\
\hline$\left({ }^{\circ} \mathrm{C}\right)$ & $(\mathrm{K})$ & & & \\
\hline 15 & 288 & \multirow{4}{*}{0.46} & \multirow{4}{*}{73.89} & -58.98 \\
\hline 25 & 298 & & & -63.59 \\
\hline 35 & 308 & & & -68.21 \\
\hline 45 & 318 & & & -72.82 \\
\hline
\end{tabular}

Table 3: Thermodynamic parameters of LAS adsorption by ACLW (m/V=0.4 $\left.\mathrm{gL}^{-1} ; \mathrm{pH} 2.5 ; 100 \mathrm{rpm}\right)$

The negative values of Gibb's free energy $\left(\Delta \mathrm{G}^{0}\right)$ prove the spontaneity of the adsorption process. The enthalpy value $\left(\Delta \mathrm{H}^{0}\right)$ of $+73.89 \mathrm{~kJ} \mathrm{~mol}^{-1}$ represents an endothermic process and strong physical adsorption or chemical adsorption, as by electrostatic interactions (which have enthalpy values in the order of 20 to 80 $\mathrm{kJ} \mathrm{mol}^{-1}$ according to Bonilla-Petriciolet et al. (2017)). Still, it is possible that both bonds, physical and chemical, coexist in different parts of the adsorbent particle, which is not homogeneous and has different active sites (Manera et al. 2018). As "-T. $\Delta \mathrm{S}^{0}$ " is of greater magnitude than " $\Delta \mathrm{H}^{0}$ ", it is assumed that adsorption is a process controlled by entropy (Bonilla-Petriciolet et al. 2017), usually occurring in high concentrations of surfactant (Somasudaram et al. 1998).

Fig. 3 shows the effect of micelle formation, in a logarithmic graph of isotherms in initial LAS concentrations from 0.05 to $1.6 \mathrm{~g} \mathrm{~L}^{-1}$, considering the ACLW surface area of $800.4 \mathrm{~m}^{2} \mathrm{~g}^{-1}$ (Manera et al. 2016). As proposed by Chang et al. (2018) and Paria and Khilar (2004), the surfactant adsorption isotherm 
in hydrophilic solids generally presents 4 distinct regions, referring to the molecular and micellar arrangement, also highlighted in Fig. 3.

Fig. 3: LAS adsorption isotherm at initial concentrations from 50 to $1600 \mathrm{mg} \mathrm{L}^{-1}\left(\mathrm{~m} / \mathrm{V}=0.4 \mathrm{gL}^{-1} ; \mathrm{pH}=2.5\right.$; 100rpm)

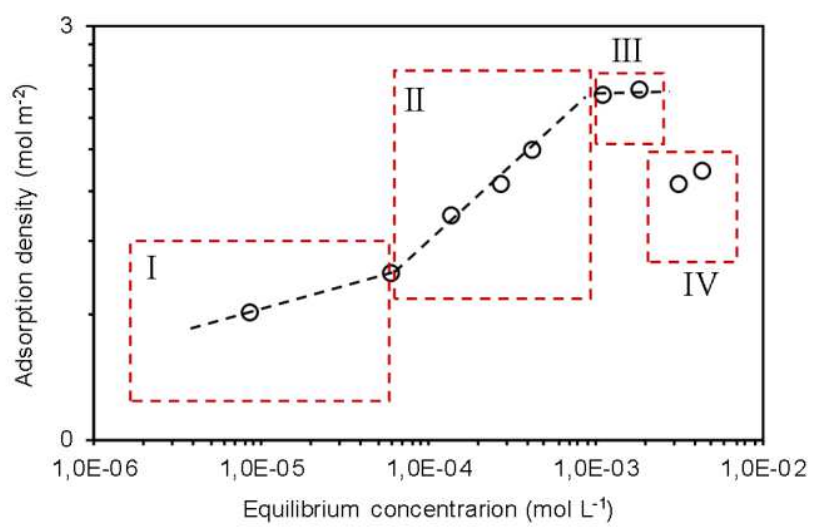

Initially, adsorption in step I is less intense than in step II, where the surfactant molecules start to become perpendicular to the surface of the adsorbent, increasing the availability of the adsorption sites. A reduction in this intensity is observed in step III, when hemi-micelles start to form, an overlap due to the lateral attractiveness of the hydrophobic group of the surfactants, turning the polar end to the adsorbate and water molecules, which is also polar (Chang et al. 2018; Paria and Khilar 2004). An increase in the adsorption density caused the enthalpy to decrease until reaching an equilibrium state (step III), leading to a "break" in the isotherm, where the simultaneous interaction between the surfactant molecules, the surface of the adsorbent and the hydrophobic part of the surfactant (Somasundaran et al. 1998).

In step IV, the critical concentration of micelles occurs, stagnating the adsorption capacity, and in some cases, reducing this capacity, as observed in this experiment. This is because the surfactant molecules are more attracted to their micelles than to the adsorbent (Paria and Khilar 2004). Therefore, the formation of micelles in the equilibrium solution is detrimental to the adsorption capacity.

Regarding the influence of the presence of electrolytes, Fig. 4 demonstrates the decline in adsorption capacity, in a linear tendency line, up to $50 \%$ saturation by $\mathrm{NaCl}$. This means that salt saturation competes with LAS adsorption and would reduce the adsorption capacity by $19.67 \mathrm{mg} \mathrm{g}^{-1}$. This indicates the proportion in which the $\mathrm{Cl}^{-}$anions take place of the $\mathrm{SO}_{3}{ }^{-}$in the active sites.

\subsubsection{Adsorption kinetics}

The adsorption kinetics of LAS by ACLW data is shown in Fig. 1c. It is observed that an initial increase in the adsorption capacity, especially in temperature of $35^{\circ} \mathrm{C}$. In this condition, the maximum adsorption capacity is observed after 100 min of contact. Table 4 summarizes the kinetic parameters of the pseudofirst and pseudo-second order models estimated for LAS adsorption on ACLW. The adjusted $\mathrm{R}^{2}$ values varied between 0.76 and 0.88 , and between 0.88 and 0.95 for pseudo first order and pseudo second-order, respectively, which guides the best fitting to the second model (solid lines in the Fig. 1c), which also presents minor SSE errors. 
Fig. 4: Influence of the presence of $\mathrm{NaCl}$ electrolyte on LAS adsorption $\left(\mathrm{C} 0=100 \mathrm{mg} \mathrm{L}^{-1} ; \mathrm{m} / \mathrm{V}=1.0 \mathrm{~g} \mathrm{~L}^{1}\right.$; $\left.12 \mathrm{~h} ; 25^{\circ} \mathrm{C} ; \mathrm{pH} 2.5 ; 100 \mathrm{rpm}\right)$

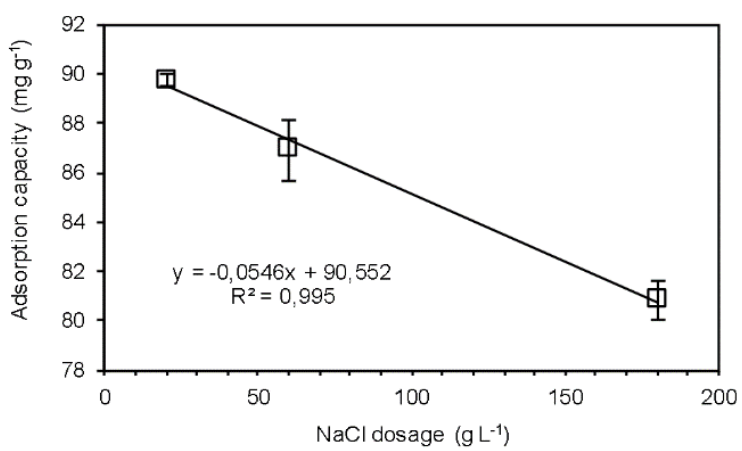

Table 4: Parameters of the kinetic models adjusted to the experimental data of LAS adsorption by ACLW

\begin{tabular}{|c|c|c|c|c|c|c|}
\hline \multicolumn{7}{|c|}{$\left(\mathrm{C}_{0}=100 \mathrm{mg} \mathrm{L}^{-1} ; \mathrm{m} / \mathrm{V}=0.2 \mathrm{~g} \mathrm{~L}^{-1} ; \mathrm{pH} 2.5 ; 100 \mathrm{rpm}\right)$} \\
\hline \multicolumn{7}{|c|}{ Pseudo first-order model } \\
\hline $\begin{array}{c}\mathbf{T} \\
\left({ }^{\circ} \mathbf{C}\right)\end{array}$ & $\begin{array}{c}\mathrm{q}_{\mathrm{e}, 1} \\
\left(\mathrm{mg} \mathrm{g}^{-1}\right)\end{array}$ & $\begin{array}{c}\mathbf{K}_{1} \\
\left(\min ^{-1}\right)\end{array}$ & $\mathbf{R}^{2}$ & $\mathbf{R}_{\text {aj }}^{2}$ & SSE & $\begin{array}{c}\mathbf{q}_{\mathrm{e} \cdot \exp } \\
\left(\mathrm{mg} \mathrm{g}^{-\mathbf{1}}\right)\end{array}$ \\
\hline 15 & 225.2 & 0.08533 & 0.7707 & 0.7612 & 33.2 & 268.3 \\
\hline 25 & 220.6 & 0.07051 & 0.8607 & 0.8566 & 22.9 & 252.7 \\
\hline 35 & 240.8 & 0.16097 & 0.8833 & 0.8774 & 25.4 & 274.3 \\
\hline 45 & 200.5 & 0.21304 & 0.8797 & 0.8730 & 21.9 & 233.5 \\
\hline \multicolumn{7}{|c|}{ Pseudo second-order model } \\
\hline $\begin{array}{c}\mathbf{T} \\
\left({ }^{\circ} \mathbf{C}\right)\end{array}$ & $\begin{array}{c}q_{e, 2} \\
\left(\mathrm{mg} \mathrm{g}^{-1}\right)\end{array}$ & $\begin{array}{c}\mathrm{K}_{2} \\
\left(\mathrm{~g} \mathrm{mg}^{-1} \mathrm{~min}^{-1}\right)\end{array}$ & $\mathbf{R}^{2}$ & $\mathbf{R}_{\text {aj }}^{2}$ & SSE & $\begin{array}{c}q_{\mathrm{e}, \exp } \\
\left(\mathrm{mg} \mathrm{g}^{-1}\right)\end{array}$ \\
\hline 15 & 245.7 & 0.00048 & 0.8873 & 0.8826 & 23.3 & 268.3 \\
\hline 25 & 235.8 & 0.00043 & 0.9474 & 0.9458 & 14.1 & 252.7 \\
\hline 35 & 255.5 & 0.00094 & 0.9474 & 0.9447 & 18.0 & 274.3 \\
\hline 45 & 215.7 & 0.00144 & 0.9390 & 0.9356 & 15.6 & 233.5 \\
\hline
\end{tabular}

The second order model was the one that best predicted the equilibrium capacity observed in the isotherms. This model assumes that different adsorption sites on an adsorbent particle randomly collide with each other during a rate-limiting step (Hubbe et al. 2019). In Fig. 1c can be observed two portions in the kinetic. Firstly, a rapid increase in adsorption capacity until close to 30 minutes. After this time, the adsorption density smoothes, indicating a gradual adsorption. Shami et al. (2020) observed a similar effect on the adsorption of surfactant sodium dodecyl sulfate on dolochar, and observed that these two steps represent that boundary layer diffusion can be considered the rate-limiting step in the initial adsorption phase and intraparticle diffusion is the rate limiting step in the final step.

Although the models indicate a lower adsorption capacity in equilibrium for the temperature of $45{ }^{\circ} \mathrm{C}$, the constants $\mathrm{K}_{1}$ and $\mathrm{K}_{2}$ are higher for this temperature, which represents a fast adsorption in the initial moments of contact between the adsorbent and the adsorbate, indicating high mass transfer rate. The increase in temperature is directly responsible for reducing the viscosity of the liquid medium, resulting in easier 
internal diffusion in the pores (Piccin et al. 2013).

295 The effect of temperature in the adoption kinetic is investigated by the Arrhenius theory. According to her, the adsorption kinetic constant correlates with temperature according to the equation 11:

$$
\mathrm{K}=\mathrm{K}^{0} \exp \left(\frac{-E_{a}}{R T}\right)
$$

where, $\mathrm{K}^{0}$ the frequency factor and $\mathrm{E}_{\mathrm{a}}$ the activation energy $\left(\mathrm{kJ} \mathrm{mol}^{-1}\right)$. The pseudo second-order kinetic constants can be applied to find the activation energy. Fig. 5 shows the Arrhenius plot, which correlates the kinetic constant with temperature. The activation energy, obtained by the slope of the Arrhenius graph divided by the ideal gas constant, is $27.4 \mathrm{~kJ} \mathrm{~mol}^{-1}$. According to the description of the adsorption mechanisms proposed by Inglezakis and Zorpas (2012), this value is common for physical adsorption or ion exchanges. According to Piccin et al. (2017), this activation energy shows an adsorption by electrostatic interaction, this is also explained because the isotherm is of the H1 type of Giles et al. (1961), in which the adsorption can occur by chemical adsorption or electrostatics interactions.

Fig. 5: Arrhenius plot of LAS adsorption by ACLW kinetic $\left(\mathrm{C}_{0}=100 \mathrm{mgL}^{-1} ; \mathrm{m} / \mathrm{V}=0.2 \mathrm{gL}^{-1} ; \mathrm{pH} 2.5\right.$;

100rpm)

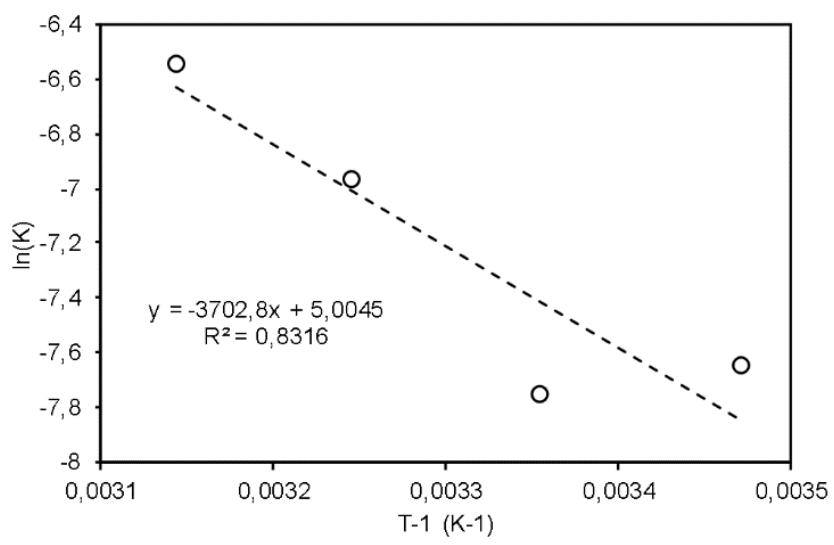

\subsection{Regeneration by desorption cycles}

Adsorption regeneration cycles can be viewed in the Fig. 1d. Ethanol desorption was carried out in duplicate to evaluate the ACLW life cycle, after 10 adsorption/desorption cycles. The removal values decreased from $80.44 \%$ to $29.70 \%$ in the last cycle, indicating a decrease in the capacity of the adsorbent material over the adsorption cycles. However, it is possible to conclude that the adsorbent material has 7 to 9 reuse cycles, as it presents efficiency higher than $50 \%$ of the initial value.

During the desorption tests it was possible to observe that the efficiency of the eluent in removing LAS from the adsorbent varied between $72.90 \%$ to $116.52 \%$, in relation to the previous cycle. In this context, after ten cycles, the sum up of adsorption capacities was $481.59 \mathrm{mg} \mathrm{g}^{-1}$. The desorption tests applied by Manera et al. (2018) showed regeneration efficiencies close to $50 \%$, applying $\mathrm{NaOH}$ as eluent. Thus, the authors determined that not only does an adsorption of a physical nature occur on the activated carbon, but determined that the adsorption energy occurs heterogeneously on the surface of his.

\subsection{Adsorption mechanisms}


Therefore, based on the theory of hydrophilic adsorbents, as is the case of the carboxyl and lactone groupings (Manera et al. 2018), and also of the amine groups present in leather residues (Mi-na et al. 2006), it is assumed that some surfactant molecules adsorbed on active sites of functional groups of strong polarity or attractiveness with their sulfonate functional group $\left(\mathrm{SO}_{3}^{-}\right)$are bound by ionic exchanges and strong electrostatic interactions. Therefore, this nature of adsorption is often considered chemical, when what possibly occurs is an adsorption of heterogeneous nature. Still, since it is a heterogeneous adsorbent, ethanol is an non-polar substance, and surfactants have an non-polar tail, two possibilities are assumed: i) that the polar connection between the eluent and the surfactant occurs more intensely than the adsorption; and ii) there may be nonpolar links occurring between surfactant and nonpolar regions of the heterogeneous adsorbent. The best efficiency resulting from ethanol desorption may be due to nonpolar interactions between the surfactant tail and the reagent. Fig. 6 illustrates the LAS desorption process from this point of view.

Fig. 6: LAS desorption process of heterogeneous surface hydrophilic adsorbent

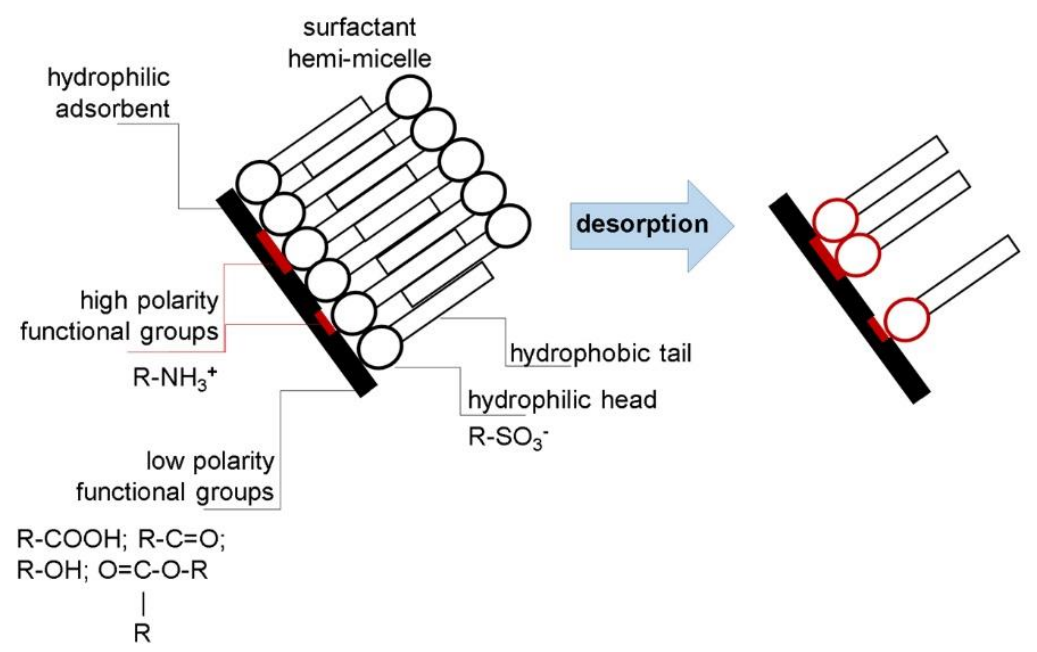

\subsection{Greywater treatment}

The raw greywater wastewater collected in a domestic bath was treated with of activated carbon from leather shave waste dosage between 0.2 and $3.0 \mathrm{~g} \mathrm{~L}^{-1}$, and its UV-VIS spectrum was determined by spectrophotometry scan, due to estimate the reduction in the presence of dissolved contaminants related to its spectra behaviour (Santos et al. 2015). The composition of greywater varies a lot depending on the hygiene habits of each person. Based on this, the absorbance scanning method in a UV-Vis spectrophotometer is suitable to verify the efficiency of the treatment techniques applied to this type of wastewater. Fig. 7 shows the summarized data of real greywater treatment by ACLW.

Fig. 7: Real greywater treatment by adsorption using ACLW: a)UV-Vis spectrum of raw greywater wastewater and its treatments by different dosages of ACLW, ranging from 0.2 to $3.0 \mathrm{~g} \mathrm{~L}^{-1}$; b) Efficiency of reducing contaminants in greywater wastewater by ACLW adsorption; and c) Effect of adsorbent dosage on anionic surfactants removal in the domestic bath greywater treatment $\left(25^{\circ} \mathrm{C} ; 100 \mathrm{rpm}\right)$ 
a)

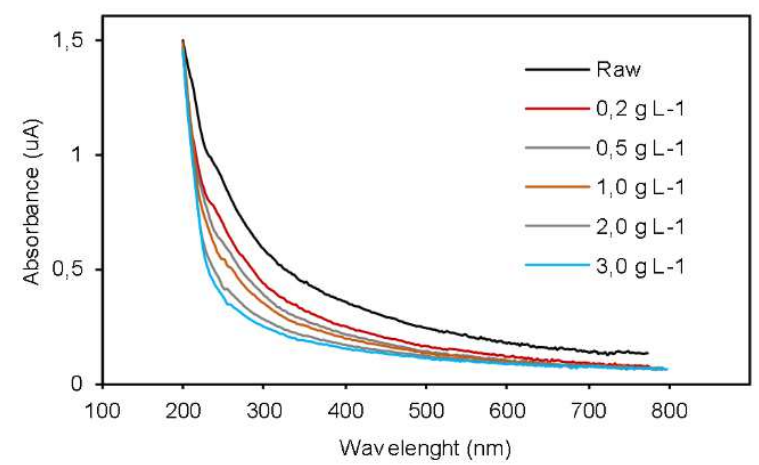

b)

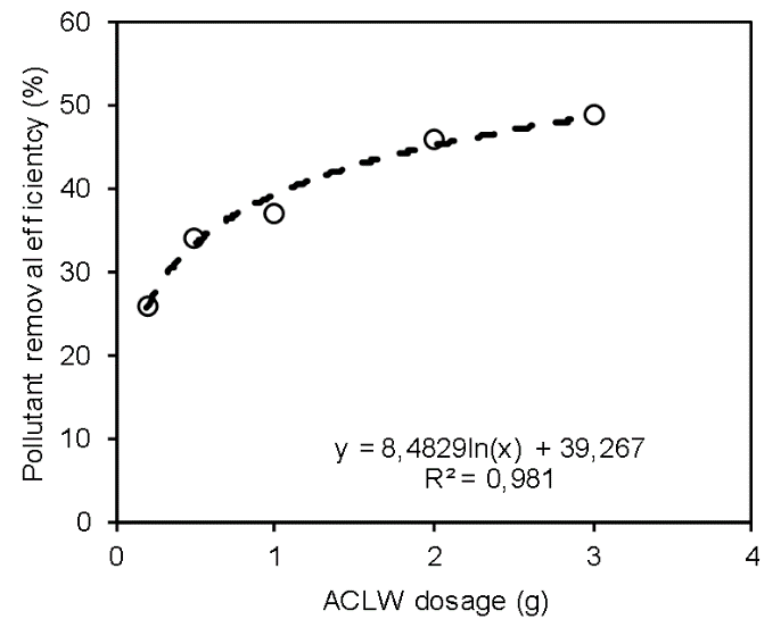

c)

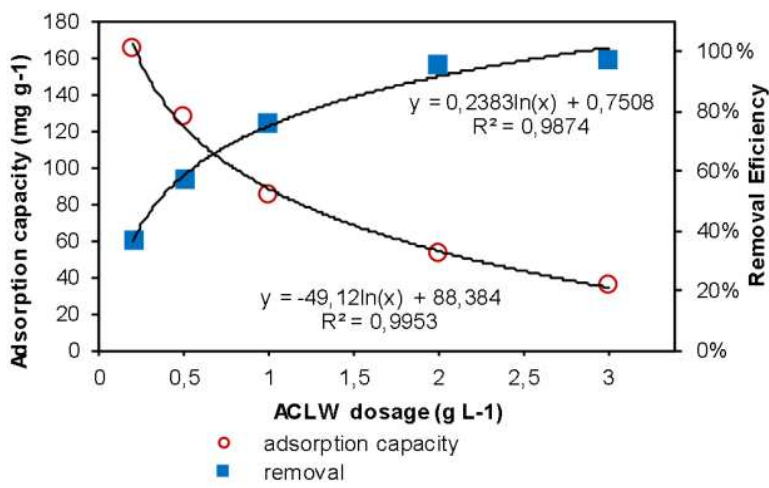

For the considerations of this test, all absorbance values were considered as contaminants. For this convention, the gradual addition of ACLW adsorbent directly contributed to the reduction of these probable contaminants, and, with an analysis of the data, the behaviour approaches a logarithmic scale, as shown in Fig. 7a $\left(\mathrm{R}^{2}=0.981\right)$. The best results obtained were for the highest ACLW dosages, with a tendency towards stabilization, where diluted substances would no longer be susceptible to removal by adsorption. Among them, possible cationic or non-ionic substances, including surfactants, or others not compatible for the ACLW active sites under the conditions of the experiments.

For all treatments, the removal of anionic surfactants was monitored. Fig. 7b shows the results of adsorbent dosage effect in the removal of anionic surfactants from the real wastewater. The removal of anionic surfactants was greater than $95 \%$ in the treatment by adsorption in doses of ACLW of $2.0 \mathrm{~g} \mathrm{~L}^{-1}$. At this dosage, the adsorption capacity was $52.69 \mathrm{mg} \mathrm{g}^{-1}$, reaching a final concentration of $4.6 \mathrm{mg} \mathrm{L}^{-1}$. The trend of decreasing adsorption capacity with increasing adsorbent mass is usual. This is due to the proportional increase in active adsorption sites, which can overcome the demand for adsorbent molecules at the time of adsorbent saturation (Yagub et al. 2014).

In Fig. 7c it is observed that the increase in adsorbent dosage causes an inverse effect on removal and adsorption capacity. This is because with the increase of the adsorbent mass, a greater number of adsorption sites are available, causing the removal percentage to increase, and the adsorption capacity to decrease due to the lower availability of adsorbate mass per adsorbent mass. 
The removal of aqueous LAS solution at $100 \mathrm{mg} \mathrm{L}^{-1}$ in the kinetic tests was $40 \%$ in 60 minutes of testing, very close to that observed in this treatment of real wastewater, where a dosage of $0.2 \mathrm{~g} \mathrm{~L}^{-1}$ was also applied and a $37 \%$ removal was obtained. Colour was noted to reduce from 335 to 225 Hazens and turbidity varied from $102 \mathrm{NTU}$ in the raw wastewater to $54 \mathrm{NTU}$ after treatment (data not showed) with $2.0 \mathrm{~g} \mathrm{~L}^{-1}$.

\section{CONCLUSIONS}

This study investigated the ideal $\mathrm{pH}$ of LAS adsorption on activated carbon made from activated carbon obtained from leather shave waste. The adsorbent material showed promising application in the adsorption of this emerging contaminant, both in tests in aqueous solution and in real wastewater of domestic greywater.

The equilibrium isotherms were of high affinity, which correlated better with the Freundlich and RedlichPeterson models. Adsorption thermodynamic was a spontaneous and endothermic process, indicating the formation of hemi-micelles on the adsorption surface. The kinetic tests correlated better with the pseudo second-order model.

Desorption was well succeeded by ethanol, which proposes that the surface of the adsorbent is heterogeneous, with physical, electrostatic and chemical bonds coexisting, in addition to polar and nonpolar bonds between surfactants and active groups of ACLW. The application of treatment in real wastewater was able to remove contaminants from greywater, especially anionic surfactants with up to $95 \%$ removal efficiency.

\section{ABBREVIATIONS}

ACLW - Activated carbon from leather shave waste;

LAS - Alkylbenzene Sulfonate Linear

pHPZC - Point of zero charge;

SDBS - Sodium Dodecyl Benzene Sulfonate

SSE - Sem standard error

\section{DECLARATIONS}

\section{Ethics approval and consent to participate}

Not applicable.

\section{Consent for publication}

Not applicable.

\section{Availability of data and materials}

Not applicable.

\section{Competing interests}


The authors declare that they have no competing interests.

\section{Funding}

Not applicable.

\section{Authors' contributions}

Henrique Baldi Faccenda: Investigation, Data curation, Writing-Original draft preparation, and Writing-

Reviewing; Flávia Melara: Writing-Original draft preparation; Gabriel Damini: Investigation and Validation; Marcelo Godinho: Investigation Christian Manera: Investigation; Jeferson Steffanello

Piccin: Project administration, Supervision, and Writing-Reviewing and Editing.

\section{ACKNOWLEDGMENT}

The authors acknowledge to the University of Passo Fundo for the scholarship and to National Council for

\section{REFERENCES}

Apha, American Public Health Association (2017) Standard Methods for the examination of water and wastewater, American Water Works Association, Water Environmental Federation. 23th edition, Washington.

BNDES - Banco Nacional do Desenvolvimento (2014) Potencial de diversificação da indústria química brasileira: Relatório 4 - tensoativos (Diversification potential of the Brazilian chemical industry: Report 4 - surfactants). Rio de Janeiro, Brazil

Bonilla-Petriciolet A, Mendoza-Castillo DI, Reynel-Ávila HE (2017) Introduction. In: Adsorption processes for water treatment and purification. Gewerbestrasse, Springer

Bonilla-Petriciolet A, Mendonza-Castillo DI, Dotto GL, Duran-Valle CJ (2019) Adsorption in water treatment. Reference module in chemistry, molecular sciences and chemical engineering, 1st edn. Elsevier, Amsterdam, pp. 1-21. DOI: https://doi.org/10.1016/ B978-0-12-409547-2.14390-2

Brandt KK, Hesselsoe M, Roslev P, Henriksen K, Sorensen J (2001) Toxic effects of linear alkylbenzene sulfonate on metabolic activity, growth rate, and microcolony formation of nitrosomonas and nitrosospira strains. Appl Environ Microbiol 67:2489-2498. https://doi.org/10.1128/AEM.67.6.2489-2498.2001

Chang Z, Chen X, Peng Y (2018) The adsorption behavior of surfactants on mineral surfaces in the presence of electrolytes - A critical review. Miner Eng 121:66-76. https://doi.org/10.1016/j.mineng.2018.03.002

Cooney DO (1998) Adsorption design for wastewater treatment. New York: CRC Press LCC

Freundlich HMF (1906) Over the adsorption in solution. J Phys Chem 57: 1100-1107

Giles CH, Macewan TH, Nakhwa SN, Smith D (1960) Studies in adsorption. Part XI. A system of classification of solution adsorption isotherms, and its use in diagnosis of adsorption mechanisms and in measurement of specific surface areas of solids. J Chem Soc 3973- 3993:3973. https://doi.org/10.1039/JR9600003973

Ho YS, Mckay G (2000) The Kinetics of sorption of divalent metal ions onto sphagnum moss peat. Water Res 34:735-742. https://doi.org/ 10.1016/S0043-1354(99)00232-8

Hubbe MA, Azizian S, Douven S (2019) Implications of apparent pseudo-second-order adsorption kinetics 
onto cellulosic materials: A review. BioResources 14: 7582-7626.

Inglezakis VJ, ZORPAS AA (2012) Heat of adsorption, adsorption energy and activation energy in adsorption and ion exchange systems. Desalin Water Treat 39:149-157. https://doi.org/10.1080/19443994.2012.669169

Jurado E, Fernández-Serrano M, Núñez-Olea J, Lechuga M, Ríos F (2011) Ecotoxicity of anionic surfactants. Trans Ecol Environ 144:497-506. https://doi.org/10.2495/ECO110431

Knepper TP, Berna JL (2003) Surfactants: properties, production, and environmental aspects. Compr Anal Chem 40:1-49. https://doi.org/10.1016/S0166-526X(03)40004-4

Kumar S, Kirha TJ, Thonger T (2014) Toxicological effects of sodium dodecyl sulfate. J Chem Pharm Res 6(5):1488-1492

Lagergren SK (1898) About the theory of so-called adsorption of soluble substances. K Sven Vetenskapsakad Handl 24:1-39

Langmuir I (1918) The adsorption of gases on plane surfaces of glass, mica and platinum. J Am Chem Soc 40:1361-1403. https://doi.org/ 10.1021/ja02242a004

Manera C, Poli JV, Poletto P, Ferreira SD, Dettmer A, Wander PR, Godinho M (2016) Activated Carbon from Leather Shaving Waste, Part II. Effect of char demineralization and activation time on surface area and pore size distribution. J. Am. Leather Chem. Assoc. 111:4

Manera C, Tonello AP, Perondi D, Godinho M (2018) Adsorption of leather dyes on activated carbon from leather shaving wastes: kinetics, equilibrium and thermodynamics studies. Environ Technol 40(21):27562768. https://doi.org/10.1080/09593330.2018.1452984

Mi-Na Z, Xue-Pin L, Bi S (2006) Adsorption of surfactants on chromium leather waste. J Soc Leath Tech Ch 90:1

\section{OECD 2005 https://hpvchemicals.oecd.org/ui/handler.axd?id=5b837fb0-350c-4742-914e-5f6513df120a}

Palmer M, Hatley H (2018) The role of surfactants in wastewater treatment: Impact, removal and future techniques: A critical review. Water Res 147:60-72. https://doi.org/10.1016/j.watres.2018.09.039

Paria S, Khilar KC (2004) A review on experimental studies of surfactant adsorption at the hydrophilic solid-water interface. Adv Colloid Interface Sci 110(3):75-95. https://doi.org/10.1016/j.cis.2004.03.001

Patil YM, Munavalli GR (2016) Performance evaluation of an integrated on-site greywater treatment system in a tropical region. Ecol Eng 95:492-500. https://doi.org/10.1016/j.ecoleng.2016.06.078

Petrovic M, Gonzalez S, Barcelo D (2003) Analysis and removal of emerging contaminants in wastewater and drinking water. Trend Anal Chem 22(10):685-698. https://doi.org/10.1016/S0165-9936(03)01105-1

Piccin JS, Cadaval TRS, Pinto LAA, Dotto GL (2017) Adsorption isotherms in liquid phase: experimental, modelling and interpretations. In: Adsorption processes for water treatment and purification. Gewerbestrasse: Springer, 19-51. https://doi.org/10.1007/978-3-319-58136-1_2

Piccin JS, Feris LA, Cooper M, Guterres M (2013) Dye Adsorption by Leather Waste: Mechanism Diffusion, Nature Studies, and Thermodynamic Data. J Chem Eng Data 58(4):873-882. https://doi.org/10.1021/je301076n

Rampelotto G (2014) Caracterização e tratamento de águas cinzas visando reúso doméstico (Characterization and treatment of gray waters for domestic reuse). Master Thesis. Federal University of Santa Maria. Santa Maria, Brazil

Rebello S, Asok AK, Mundayoor S, Jisha MS (2013) Surfactants: Chemistry, Toxicity and Remediation. In: Lichtfouse E., Schwarzbauer J., Robert D. (eds) Pollutant Diseases, Remediation and Recycling. 
Environmental Chemistry for a Sustainable World 4, Switzerland: Springer, 277-320.

Redlich OJDL, Peterson DLA (1959) A useful adsorption isotherm. J Phys Chem 63:1024-1024. https://doi.org/10.1021/j150576a611

Santos DC, Adebayo MA, Lima EC, Pereira SFP, Cataluña R, Saucier C, Thue PS, Machado FM (2015) Application of Carbon Composite Adsorbents Prepared from Coffee Waste and Clay for the Removal of Reactive Dyes from Aqueous Solutions. J Braz Chem Soc 26(5):924-938. http://doi.org/10.5935/0103$\underline{5053.20150053}$

Schouten N, Van Der Ham LGJ, Euverink GJW, Haan AB (2009) Kinetic analysis of anionic surfactant adsorption from aqueous solution onto activated carbon and layered double hydroxide with the zero length column method. Sep Purif Technol 68(2):199-207. https://doi.org/10.1016/j.seppur.2009.05.004

Schouten N, Van Der Ham LGJ, Euverink GJW, Haan AB (2007) Selection and evaluation of adsorbents for the removal of anionic surfactants from laundry rinsing water. Water Res 41(18):4233-4241. https://doi.org/10.1016/j.watres.2007.05.044

Shami S, Rajesh RD, Verma AK, Dash AK, Pradhan A (2020) Adsorptive removal of surfactant using dolochar: A kinetic and statistical modeling approach. Water Environ. Res. 92: 222-235. https://doi.org/10.1002/wer.1193

Siyal AA, Shamsuddin MR, Low A, Rabat NE (2020) A review on recent developments in the adsorption of surfactants from wastewater. J Environ Manage 254:109797. https://doi.org/10.1016/j.jenvman.2019.109797

SNIS - Sistema Nacional de Informações Sobre Saneamento (2018) Diagnóstico dos serviços de água e esgotos - 2016 (Diagnosis of water and sewage services - 2016). Brasília, Brazil

Somasundaran P, Shrotri S, Huang L (1998) Thermodynamics of adsorption of surfactants at solid-liquid interface. Pure Appl. Chem.70 (3): 621-626.

UNESCO - United Nations Educational, Scientific and Cultural Organization (2015) Emerging Pollutants in Water and Wastewater. Available in: https://en.unesco.org/emergingpollutantsinwaterandwastewater\#: :text=These\%20contaminants\%20inclu de $\% 20$ mainly $\% 20$ chemicals,surfactants $\% 2 \mathrm{C} \% 20$ industrial\%20additives $\% 20$ and $\% 20$ solvents. Acess in: June $1^{\text {st }}, 2019$.

Wu Sh, Pendleton P (2001) Adsorption of Anionic Surfactant by Activated Carbon: Effect of Surface Chemistry, Ionic Strength, and Hydrophobicity. J Colloid Interf Sci 243(2):306-315. https://doi.org/10.1006/jcis.2001.7905

Yagub MT, Sem TK, Afroze S, Ang HM (2014) Dye and it as removal from aqueous solution by adsorption: A review. Adv Colloid Interface Sci 209:172-184. https://doi.org/10.1016/j.cis.2014.04.002

Ying GG (2006) Fate, behavior and effects of surfactants and their degradation products in the environment. Environ Int 32(3):417-431. https://doi.org/10.1016/j.envint.2005.07.004 